\title{
The impact of misdiagnosing celiac disease at a referral centre
}

\author{
Federico Biagi MD, Paola I Bianchi MD, Jonia Campanella MD, Giovanni Zanellati MD, Gino R Corazza MD
}

\begin{abstract}
F Biagi, PI Bianchi, J Campanella, G Zanellati, GR Corazza. The impact of misdiagnosing celiac disease at a referral centre. Can J Gastroenterol 2009;23(8):543-545.
\end{abstract}

In the past few years, the number of celiac disease diagnoses not confirmed at the Fondazione IRCCS Policlinico San Matteo, Pavia, Italy, a tertiary referral centre, was particularly high. Therefore, a decision was made to investigate the reasons why these diagnoses were wrong and by whom they had been made. The clinical histories of all celiac patients referred to the centre were re-evaluated. Between December 1998 and January 2007, 614 patients who were diagnosed at other institutions and presumed to be affected by celiac disease attended the tertiary referral outpatient clinic. The histological and serological results allowed for confirmation the diagnosis in 434 patients. In the remaining 180 patients, the initial diagnosis of celiac disease could not be confirmed; therefore, the patients were re-investigated. After re-evaluation, the diagnosis of celiac disease was confirmed in only 61 of these 180 cases. The reasons for incorrect initial diagnosis were analyzed. A mere $80 \%$ correct diagnosis rate is a very disappointing result. Although it should be obvious that celiac disease must be investigated with duodenal biopsies and celiac antibody testing, this well-known strategy is not always followed, probably resulting in an incorrect diagnosis.

Key Words: Celiac disease; Endomysial antibodies; Gluten-free diet; Tissue transglutaminase antibodies; Villous atrophy

$\mathrm{D}$ ue to its high prevalence (1), interest in celiac disease (CD) has increased in the past few years, not only among gastroenterologists but also among patients and general practitioners (2).

Our celiac outpatient clinic at the Fondazione IRCCS Policlinico San Matteo, Pavia, Italy, is a tertiary referral centre that sees patients who were diagnosed with $C D$ at other hospitals, not only to provide them with gluten-free food certificates and regional health service tax exemptions, but also because of the persistence of their symptoms. One important aspect of our clinical work is represented by celiac patients in whom, due to a lack of clinical response to a gluten-free diet, refractory $\mathrm{CD}$ is suspected. Because it was shown that failure to respond to a gluten-free diet should always raise doubts regarding the initial diagnosis (3), it is mandatory in our clinic to verify whether all of these patients are actually affected by CD.

In the past few years, we were under the impression that the number of diagnoses of CD not confirmed by our centre was particularly high and due to diagnoses of CD based on Marsh 1and Marsh 2-type lesions (4), also known as 'minimal intestinal lesions', or in spite of negative celiac antibody results. To clarify our clinical point of view, we believe that a diagnosis of $\mathrm{CD}$ in patients with minimal intestinal lesions or who are

\section{Impact des erreurs diagnostiques relatives à la maladie coliaque dans un centre de référence}

\begin{abstract}
Au cours des quelques dernières années, à la Fondazione IRCCS Policlinico San Matteo, de Pavie, en Italie, un centre de référence tertiaire, le nombre de diagnostics de maladie cœliaque non confirmés, était particulièrement élevé. Il a donc été décidé d'explorer pourquoi ces diagnostics étaient erronés et par qui ils avaient été posés. L'histoire clinique de tous les patients cœliaques adressés au centre a donc été réévaluée. Entre décembre 1998 et janvier 2007, 614 patients ayant reçu un diagnostic dans d'autres établissements et présumés atteints de maladie cœliaque se sont présentés à la clinique ambulatoire du centre de référence tertiaire. Les résultats histologiques et sérologiques ont permis de confirmer le diagnostic chez 434 patients. Chez les 180 autres patients, le diagnostic initial de maladie cœliaque n'a pas pu être confirmé. Par conséquent, les patients ont subi de nouveaux examens. Après réévaluation, le diagnostic de maladie coliaque a été confirmé chez 61 patients seulement parmi ces 180 cas. Les raisons du diagnostic initial erroné ont été analysées. Un taux de diagnostics corrects de $80 \%$ est très décevant. Il semble évident que la maladie cœliaque doit faire l'objet d'investigations au moyen de biopsies duodénales et de dosages des anticorps cœliaques, mais cette stratégie pourtant bien connue n'est pas toujours suivie et explique probablement les erreurs de diagnostic.
\end{abstract}

negative for celiac antibodies, requires a great degree of skill and expertise in the celiac field (4-6). Although these two conditions certainly exist, presently, there is no consensus on how to diagnose $\mathrm{CD}$ in patients who present with minimal intestinal lesions only. Moreover, in our clinical experience, such lesions are rare and we believe that their epidemiological relevance has been greatly overestimated in the past few years. We have recently shown (7) that minimal intestinal lesions are uncommon and are not inevitably due to $\mathrm{CD}$. In the past 10 years, we have found only three patients who were affected by untreated $\mathrm{CD}$ and negative for celiac antibodies.

Therefore, we decided to re-evaluate the clinical histories of all patients referred to our centre. An incorrect diagnosis of CD represents both a risk for the health of the patient - mainly because of the necessity of a lifelong gluten-free diet - and a considerable waste of money, time and resources for institutions.

\section{METHODS}

To confirm the diagnoses of CD made in other hospitals, criteria were very strict. Only diagnoses based on a well-oriented duodenal biopsy showing unequivocal villous atrophy and positive for endomysial immunoglobulin (Ig) A (EMA) or tissue transglutaminase antibodies (TTA) (8), were initially confirmed. To be certain 
TABLE 1

\section{Reasons for questioning the initial diagnoses of celiac} disease $(n=180)$

\begin{tabular}{lc}
\hline Reason & $\mathbf{n}$ \\
\hline Duodenal biopsy not performed & 95 \\
Mild duodenal lesions and/or poor sectioning of duodenal biopsy & 63 \\
EMA/TTA tests not performed & 77 \\
Negative for EMA/TTA & 61 \\
Lack of clinical response to a gluten-free diet & 31 \\
\hline
\end{tabular}

The sum is greater than 180 because in a single patient, more than one reason was possible. Mild duodenal lesions and poor sectioning of duodenal biopsy are presented together because it was very often impossible to distinguish one problem from the other, as alluded to by Brown et al (10). EMA Endomysial antibodies; TTA Tissue transglutaminase antibodies

about the histological diagnosis, patients affected by $\mathrm{CD}$ who were diagnosed at other institutions were asked to bring their original biopsy slides to have them reviewed by staff (FB, GRC). In this outpatient clinic, it is very common to see patients who have undergone only some of the proper tests required to reach a definitive diagnosis of $\mathrm{CD}$, or patients investigated by means of totally inappropriate tests which, due to their eccentric variability, are sometimes extremely difficult to categorize. Therefore, patients who had received a formal diagnosis of CD not supported by the above mentioned, strict criteria, and patients with incomplete or inappropriate tests who, nevertheless, had already started a glutenfree diet, were considered to have a debatable diagnosis (DD).

The clinical notes of all the DD patients seen in the outpatient clinic at the Coeliac Centre/First Department of Internal Medicine at the University of Pavia, Pavia, Italy, between December 1998 and January 2007 were examined. These patients were re-evaluated by means of repeat duodenal biopsies, EMA testing on monkey esophagus substrate, evaluating total IgA levels or human leukocyte antigen typing. Because it is well known that both intestinal lesions and celiac antibodies tend to normalize while on a gluten-free diet, these tests may have been performed after gluten was reintroduced in the diet, as described previously (9).

According to the results of the re-evaluation, these patients were classified as confirmed $\mathrm{CD}$ or $\mathrm{CD}$ was excluded. The reasons for questioning the initial diagnosis of $\mathrm{CD}$ as well as whether this diagnosis had been made by a gastroenterologist, internist, general practitioner, dermatologist or other health care professional was investigated. Finally, for the patients in whom $\mathrm{CD}$ had been excluded, the diagnostic delay in reaching the final diagnosis was determined.

\section{RESULTS}

A total of 705 patients presumed to be affected by $C D$ who were diagnosed at other institutions attended the outpatient clinic for the first time. Of these 705 patients, 614 had received a formal diagnosis of $\mathrm{CD}$ at another hospital or had already started a gluten-free diet. Frank villous atrophy and positive EMA results had allowed us to confirm the initial diagnosis of CD in 434 of 614 patients $(70.7 \%)$. In the remaining 180 patients ( 129 women, mean $[ \pm$ SD] age $34 \pm 14.4$ years), the initial diagnosis of $C D$ could not be confirmed.

The reasons why the initial diagnosis of $\mathrm{CD}$ was questioned are presented in Table 1. The medical histories and the tests these patients had undergone before being investigated in our unit were clearly different. Moreover, more than one reason was applicable to most of them.

All DD patients were thoroughly reinvestigated in the unit. Gluten was reintroduced into the diet of 117 subjects, upper gastrointestinal endoscopy with duodenal biopsies was performed in 120, EMA and total IgA levels were determined in 131, and human leukocyte antigen typing was performed in 56. A diagnosis of CD was confirmed in 61 of $180 \mathrm{DD}$ patients. More precisely, the diagnosis of $\mathrm{CD}$ was based on villous atrophy and positive EMA results in 47 patients, and minimal intestinal lesions and positive EMA in 12 (six of these 12 were affected by dermatitis herpetiformis). In two patients, villous atrophy was evident but EMAs were negative due to an IgA deficiency. On the other hand, 12 patients were lost to follow-up, and in 23 patients, who either refused to reintroduce gluten into their diet (12 patients) or to repeat the duodenal biopsy (11 patients), it was impossible to confirm or exclude the diagnosis of CD. Finally, on the basis of normal duodenal mucosa, negative EMAs and normal IgA levels, CD was excluded in 84 of 180 DD patients. Thus, overall, CD was actually excluded in between 84 and 119 of 614 patients (13.6\% to $19.4 \%)$. A final conclusive diagnosis was made in 48 of 84 patients in whom CD had been excluded (irritable bowel syndrome, $\mathrm{n}=18$; food allergy, $\mathrm{n}=7$; lactose malabsorption, $\mathrm{n}=8$; infectious diarrhea, $\mathrm{n}=8$; gastroesophageal reflux disease, $\mathrm{n}=2$; microscopic colitis, $\mathrm{n}=2$; small-bowel bacterial overgrowth, $\mathrm{n}=1$; Crohn's disease, $\mathrm{n}=1$; and chronic pancreatitis, $\mathrm{n}=1$ ). In the remaining 36 subjects, a final diagnosis could not be made because $\mathrm{CD}$ had been incorrectly suspected on the basis of its putative association with another autoimmune condition $(n=8)$ or the patients continued to be followed at the referral centre once CD had been excluded. The patients in whom CD was excluded had been on a pointless gluten-free diet for seven months (interquartile range 2.25 months to 18 months) and the final diagnosis was made after a diagnostic delay of 14 months (interquartile range 6.25 months to 28 months). A diagnosis of refractory $\mathrm{CD}$ was not confirmed in any patients.

In 127 of 180 patients, the notes allowed for the identification of the health care professional who had initially considered the patient as being affected by CD (Figure 1). Surprisingly, 37 of 127 DD patients (29.1\%) had been diagnosed by gastroenterologists, but only 18 of 127 (14.2\%) by internists. Moreover, the diagnosis of $\mathrm{CD}$ performed by the gastroenterologists was confirmed in only nine of $37 \mathrm{DD}$ cases, while for the internists it was confirmed in 10 of $18 \mathrm{DD}$ patients $\left(\mathrm{P}<0.0001\left[\chi^{2}\right.\right.$ test $\left.]\right)$.

\section{DISCUSSION}

We cannot deny that we encountered several difficulties in the present study. Not only is it retrospective in nature, but it also analyzes the reasons why the initial diagnosis of $\mathrm{CD}$ was not confirmed. These reasons can vary considerably from patient to patient, and at the same time, several of them could be present in an individual. Nevertheless, the present study shows that among patients considered to be affected by CD diagnosed at other institutions, a diagnosis based on clear villous atrophy and positive EMA/TTA was performed in only 434 of 614 cases (70\%). Because $\mathrm{CD}$ is common and involves an expensive, lifelong and socially inconvenient gluten-free diet, we believe that this is a very disappointing result. Moreover, it must be stressed that in all $\mathrm{DD}$ cases, the diagnosis of $\mathrm{CD}$ will be definitively confirmed in only one-third, and no diagnosis will be reached in $20 \%$. 
At the beginning of our study, we had presumed that the main reasons for questioning a diagnosis of $\mathrm{CD}$ were related to poor duodenal biopsy quality, and/or minimal intestinal lesions and/or negativity for celiac antibodies (3-6,10). Although they turned out to be responsible for several of the DD cases, it was disappointing to see that in the majority of cases, DDs were due to the lack of performing a duodenal biopsy and/or celiac antibody testing (Table 1 ).

Presently, it is quite common to see patients who have commenced a gluten-free diet, believing they are affected by CD (9). Although it is understandable that some people regard diet as a way of understanding the origin of their symptoms, it is disappointing to realize that physicians do not discourage the practice of converting to a gluten-free diet without an accurate diagnosis. Just as disappointing is the the fact that some doctors themselves suggest the diet conversion.

We have already shown that the diagnosis of CD suffers from a considerable diagnostic delay (11). Conversely, the results of the present study show that an incorrect diagnosis of $\mathrm{CD}$ can itself cause a diagnostic delay of other conditions. Fortunately, organic diseases were found in only five patients (microscopic colitis, $\mathrm{n}=2$; Crohn's disease, $\mathrm{n}=1$; small bowel bacterial overgrowth, $\mathrm{n}=1$; and chronic pancreatitis, $\mathrm{n}=1$ ).

Although $\mathrm{CD}$ was demonstrated to be an underdiagnosed condition almost 30 years ago (12), currently, our better understanding of the possible spectrum of clinical presentations and the widespread use of celiac antibody testing allows for the correct classification of new patients belonging to documented risk groups. Nevertheless, it is not possible to avoid the fact that the majority of true $\mathrm{CD}$ patients still escape diagnosis (13). On the other hand, the present study confirms that a side effect of the greater interest shown by doctors and patients is the truly remarkable number of false diagnoses related to the administration of a gluten-free diet as a diagnostic criterion $(9,14)$, the use of inappropriate tests or to the inaccurate application and interpretation of appropriate tests. It is hoped that for a condition characterized by a high level of comorbidity and mortality, and by high costs, greater care will be taken with the diagnosis in the future (15-17).

\section{REFERENCES}

1. Mäki M, Mustalahti K, Kokkonen J, et al. Prevalence of celiac disease among children in Finland. N Engl J Med 2003;348:2517-24

2. Hin H, Bird G, Fisher P, Mahy N, Jewell D. Coeliac disease in primary care: Case finding study. BMJ 1999;318:164-7.

3. Shidrawi RG, Przemioslo R, Davies DR, Mahi N, Jewell D. Pitfalls in diagnosing coeliac disease. J Clin Pathol 1994;47:693-4.

4. Oberhuber G, Granditsch G, Vogelsang H. The histopathology of coeliac disease: Time for a standardized report scheme for pathologists. Eur J Gastroenterol Hepatol 1999;11:1185-94.

5. Rostom A, Dubé C, Cranney A, Saloojee N, Sy R, Garritty C. The diagnostic accuracy of serologic tests for celiac disease: A systematic review. Gastroenterology 2005;128:S38-46.

6. Kaukinen K, Mäki M, Partanen J, Sievänen H, Collin P. Celiac disease without villous atrophy. Revision of criteria called for. Dig Dis Sci 2001;46:879-87.

7. Biagi F, Bianchi PI, Campanella J, et al. The prevalence and the causes of minimal intestinal lesions in patients complaining of symptoms suggestive of enteropathy. A follow-up study. J Clin Pathol 2008;61:1116-8.

8. Working Group of the United European Gastroenterology Week in Amsterdam. When is a coeliac a coeliac? Eur J Gastroenterol Hepatol 2001;13:1123-8.

9. Campanella J, Biagi F, Bianchi PI, Zanellati G, Marchese A, Corazza GR. A clinical response to gluten withdrawal is not an indicator of coeliac disease. Scand J Gastroenterol 2008;43:1311-4.

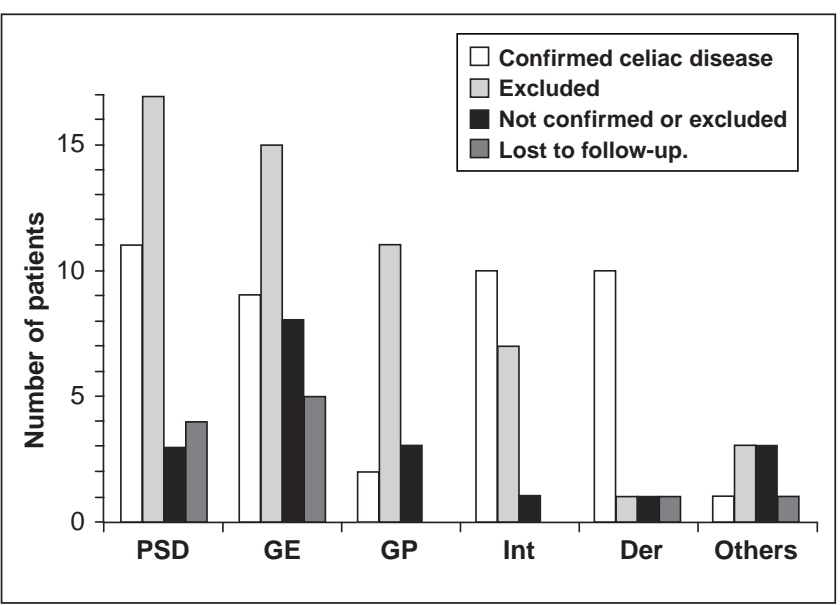

Figure 1) Health care professionals diagnosing celiac disease. Der Dermatologist; GE Gastroenterologist; GP General practitioner; Int Internist; PSD Patient self-diagnosis

\section{CONCLUSION}

By confirming that $\mathrm{CD}$ must be investigated with duodenal biopsies and EMA/TTA testing, not following this well-known strategy will probably result in an incorrect diagnosis. Moreover, we are firmly convinced that a diagnosis of $\mathrm{CD}$ with minimal intestinal lesions and negative EMA/TTA results is very risky. A gluten-free diet should be commenced only after frank villous atrophy has been proven. Patients with minimal intestinal lesions should be maintained on a gluten-containing diet and strictly followed up. It cannot be forgotten that symptom relief on a 'wheat-free' diet is totally nonspecific $(9,14,18)$. To start a gluten-free diet in these cases is not only pointless and expensive, but afterwards will also lead to expensive and potentially hazardous procedures such as a gluten challenge in a CD patient and gastroscopy with multiple biopsies. Finally, our data cannot be generalized to the entire Italian celiac population, but only for patients requesting further consultation at our referral centre.

10. Brown I, Mino-Kenudson M, Deshpande V, Lauwers GY. Intraepithelial lymphocytosis in architecturally preserved proximal small intestinal mucosa: An increasing diagnostic problem with a wide differential diagnosis. Arch Pathol Lab Med 2006;130:1020-5.

11. Corazza GR, Brusco G, Andreani ML, Biagi F, Di Stefano M, Gasbarrini G. Previous misdiagnosis and diagnostic delay in adult celiac disease. J Clin Gastroenterol 1996;22:324-5.

12. Swinson CM, Levi AJ. Is coeliac disease underdiagnosed? Br Med J 1980;281:258-60.

13. Dubé C, Rostom A, Sy R, et al. The prevalence of celiac disease in average risk and at risk Western European populations: A systematic review. Gastroenterology 2005;128:S57-67.

14. Kaukinen K, Turjanmaa K, Mäki M, et al. Intolerance to cereals is not specific for coeliac disease. Scand J Gastroenterol 2000;35:942-6.

15. Collin P, Reunala T, Pukkala E, Laippala P, Keyrilainen O, Pasternack A. Celiac disease: Associated disorders and survival. Gut 1994;35:1215-8.

16. Corrao G, Corazza GR, Bagnardi V, et al. Mortality in patients with coeliac disease and their relatives: A cohort study. Lancet 2001;358:356-61.

17. Mearin ML, Ivarsson A, Dickey W. Coeliac disease: Is it time for mass screening? Best Pract Res Clin Gastroenterol 2005;19:441-52.

18. Nanda R, James R, Smith H, Dudley CR, Jewell DP. Food intolerance and the irritable bowel syndrome. Gut 1989;30:1099-104. 


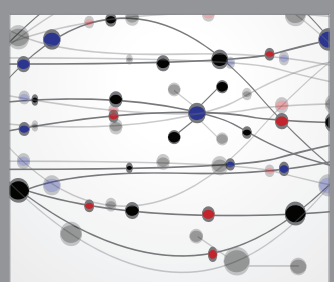

The Scientific World Journal
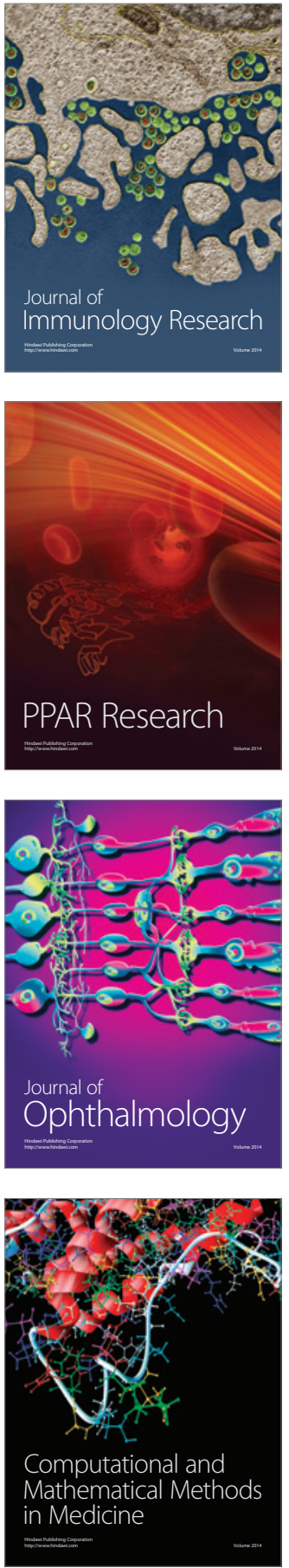

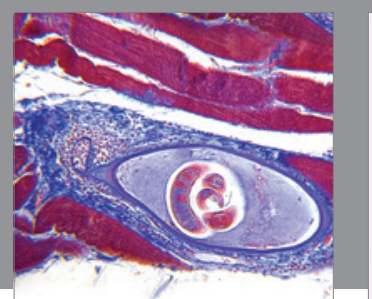

Gastroenterology Research and Practice

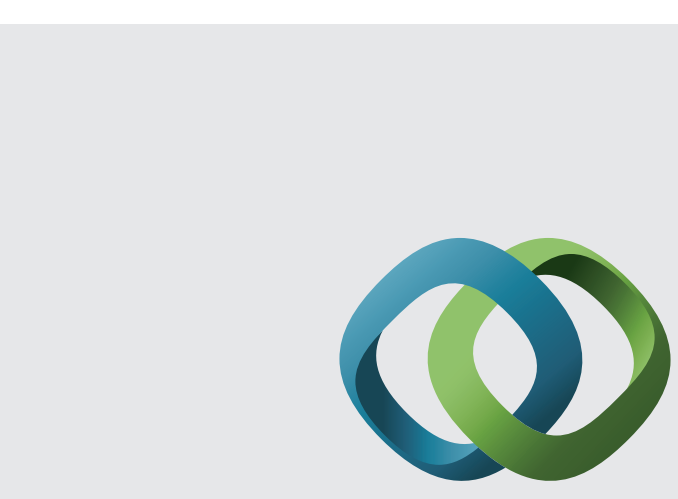

\section{Hindawi}

Submit your manuscripts at

http://www.hindawi.com
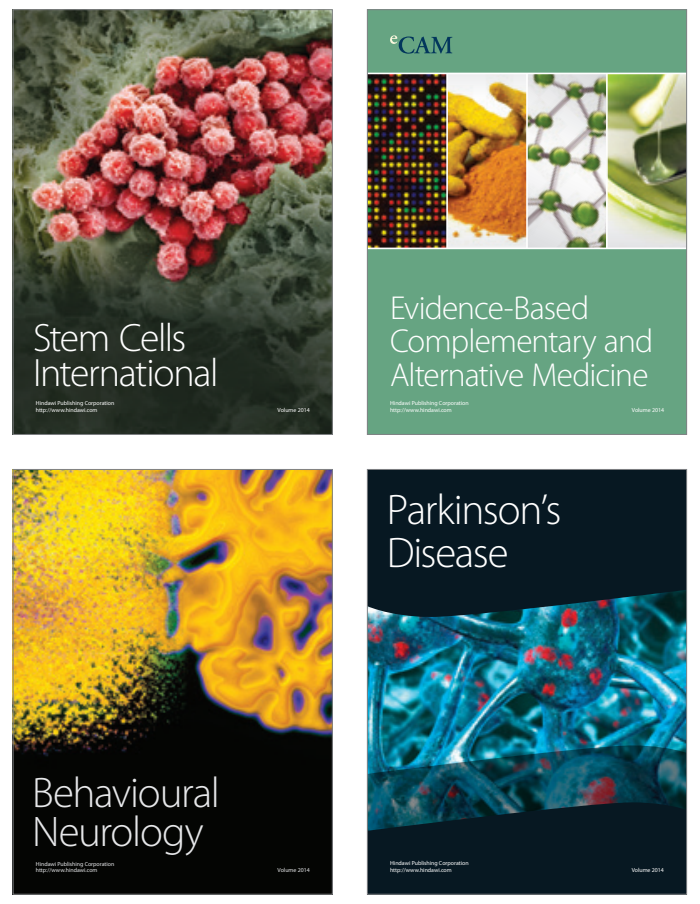
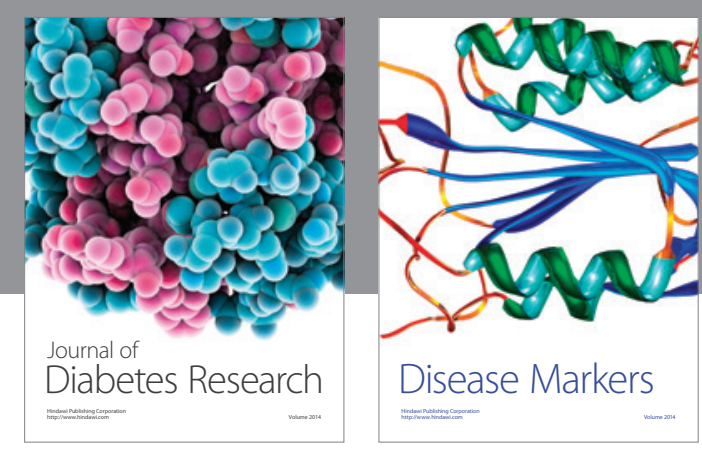

Disease Markers
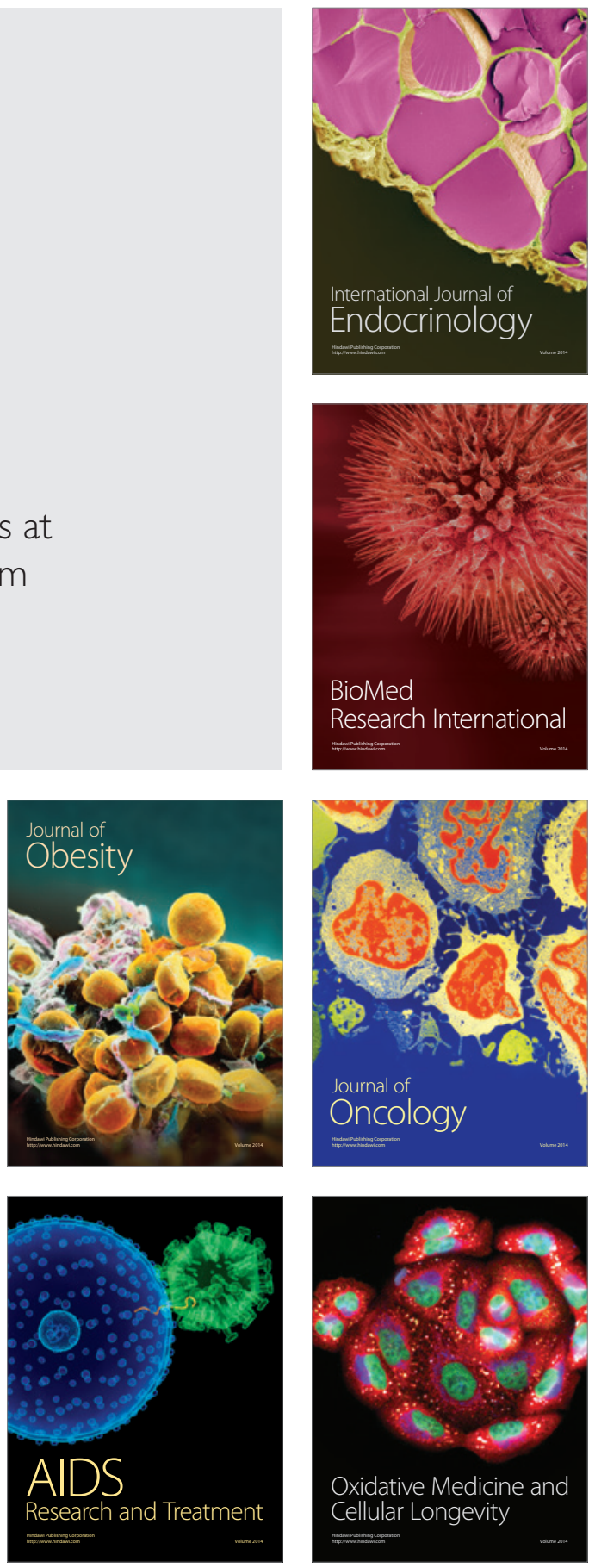